Original Article

\title{
Anagrelide reduces thrombotic risk in essential thrombocythaemia vs. hydroxyurea plus aspirin
}

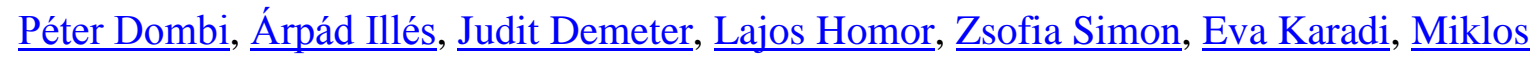
$\underline{\text { Udvardy, Miklos Egyed }}$

\section{Abstract}

\section{Objective}

To evaluate the reduction in thrombotic events (TE) in patients with essential thrombocythaemia (ET) treated with anagrelide versus hydroxyurea + aspirin (HU + ASA).

\section{Methods}

A questionnaire was developed using 2008 WHO diagnostic criteria, and thrombotic risk factors were stratified according to Landolfi criteria. Through questionnaire completion, clinicians at Hungarian haematological centres entered data into the Hungarian MPN Registry on patients with myeloproliferative neoplasms. Based on ET registry data, TEs in anagrelide-treated patients $(n=139)$ were compared with HU + ASA-treated patients $(n=$ 141).

\section{Results}

Patients were followed up for (median) 6 yr. TEs were reported in significantly fewer anagrelide-treated patients versus HU + ASA (15.1\% versus $49.6 \% ; P<0.001)$. Numbers of major arterial and major venous events were similar between the groups, although there were over fivefold more minor arterial and minor venous events in the HU + ASA group $(P<$ $0.001)$. While median age at diagnosis was older and length of follow-up shorter in the HU + ASA group $(P<0.05)$, this did not influence TE incidence; medication and TE before diagnosis only influenced TE incidence.

\section{Conclusions}

Anagrelide significantly decreased the number of patients experiencing minor arterial and minor venous TEs versus HU + ASA over 6 yr. Risk of TE after diagnosis was significantly increased if the patient had TE before diagnosis.

The myeloproliferative neoplasms (MPN), polycythaemia vera (PV), essential thrombocythaemia (ET) and primary myelofibrosis (PMF) are characterised by stem cell-derived clonal myeloproliferation $\underline{1}, \underline{2}$. Most patients with PV, ET and PMF possess a Janus kinase $2(J A K 2$; 9p24) mutation, with approximately $96 \%, 55 \%$ and $65 \%$ displaying activating mutations in $J A K 2 \mathrm{~V} 617 \mathrm{~F}$, respectively $\underline{3}-\underline{5}$. 
In PV and ET, survival or leukaemic transformation does not seem to be affected by the presence or allele burden of $J A K 2 \mathrm{~V} 617 \mathrm{~F} \underline{5}-\underline{7}$ but, in ET, the presence of $J A K 2 \mathrm{~V} 617 \mathrm{~F}$ has been associated with an increased risk of arterial thrombosis $\underline{7}, \underline{8}$. As such, the focus of risk stratification in PV and ET is the likelihood of thrombotic complications $\underline{9}$. An international study examining thrombotic risk factors in 891 patients with ET found that $109(12 \%)$ patients experienced arterial $(n=79)$ or venous $(n=37)$ thrombosis. Predictors of arterial thrombosis included an age of more than $60 \mathrm{yr}$, history of thrombosis, cardiovascular risk factors, leukocytosis $\left(>11 \times 10^{9} / \mathrm{L}\right)$ and presence of JAK2V617F; male gender only predicted venous thrombosis $\underline{8}$.

Survival rates are high in both ET and PV (80\% at $15 \mathrm{yr}$ and $75 \%$ at $10 \mathrm{yr}$, respectively) $\underline{7}, \underline{10}$, although the risk of thrombosis is $>20 \%$ in both disorders 11 . Consequently, as with risk stratification, the focus of current PV and ET management is primarily to prevent thrombo-haemorrhagic complications without increasing the risk of bleeding, but also to control symptoms $\underline{9}$.

The Hungarian MPN Working Group (HUMYPRON GROUP) was established to examine the heterogeneity of therapeutic management of MPN in Hungary. To enable this, in 2013, the HUMYPRON GROUP created an MPN Registry 12 . The MPN registry has three main areas of interest: to collect epidemiological, diagnostic, and therapeutic data, and follow-up complications and disease transformations; to investigate adherence to the WHO 2008 diagnostic criteria 1 and Landolfi therapeutic guidelines $\underline{13}$ to gain insight into vascular and haematological complications; and to identify important issues and gaps in management, and promote internationally accepted standard of care $\underline{14}$.

The MPN registry has been approved and authorised by the Hungarian authorities Egészségügyi Tudományos Tanács-Tudományos és Kutatásetikai Bizottsága (ETT-TUKEB) 12. Its computer software allows for continuing update. Data on patients with PV, ET and idiopathic myelofibrosis (IMF) are entered online into the registry. All registered haematologists entering data are permitted to initiate search and association analysis.

Controlled studies comparing anagrelide with hydroxyurea have demonstrated conflicting results with regard to protection against thrombosis $\underline{15}, \underline{16}$. Herein, based on MPN registry data, the outcomes of ET patients treated with anagrelide were compared with ET patients treated with hydroxyurea + aspirin. Specifically, the effects of treatment on thrombotic events (TEs) are reported.

\section{Patients and methods}

\section{Patients and data collection}

Data on classical MPN patients were collected electronically using an easily evaluable questionnaire, developed through close cooperation between experts in haematology and information technology. The questionnaire was developed in line with the 2008 revision of the World Health Organization (WHO) diagnostic criteria $\underline{1}$, with focus on complications, risk stratification and treatment. Thrombotic risk and the risk-adapted treatment characteristics were stratified according to the Landolfi criteria 13. Accordingly, a score (range 0-3.5) is allocated to each risk factor present: age $(<40 ; 40-55 ; 56-65 ;>65 \mathrm{yr})$, hypertension, 
dyslipidaemia, platelet count $\left(>1000 \times 10^{9} / \mathrm{L}\right)$, leucocyte count $\left(12 \times 10^{9} / \mathrm{L}\right)$, smoking, diabetes and past history of thrombosis.

Through questionnaire completion, clinicians at major and smaller haematological centres in Hungary entered data into the Hungarian MPN Registry on all patients with PV, ET and IMF who they had diagnosed using WHO criteria and treated. Based on registry data, the characteristics and outcomes of ET patients treated with anagrelide or with hydroxyurea + aspirin were extracted.

\section{Definition of thrombotic events}

Minor and major arterial and venous TEs were classified according to the following $\underline{16}$ :

1. Major arterial thrombosis, including stroke, myocardial infarction, peripheral arterial disease and other arterial thrombosis;

2. Minor arterial events, including transient ischaemic attack (TIA), angina pectoris, unstable angina, generalised convulsions, erythromelalgia, ocular symptoms, other peripheral arterial microcirculatory disturbances and other minor arterial events;

3. Major venous thrombosis, including iliofemoral thrombosis, pulmonary embolism, splanchnic vein thrombosis and other major venous events;

4. Minor venous events, including superficial thrombophlebitis, and other minor venous events.

\section{Statistical analysis}

Metric variables were compared between subgroups either by $t$-test for independent samples or by a parametric analysis of variance (anova; including post hoc tests by Hochberg's GT2 method). Comparisons of dichotomous variables were performed either by Fisher's exact test or by exact chi-square test (with provision of adjusted residuals). Logistic regression analysis was used to investigate the influence of the following covariates on TE occurrence: medication (anagrelide vs. hydroxyurea + aspirin), length of follow-up, Landolfi risk summary score, age at diagnosis (in years or $<60 \mathrm{yr} v s . \geq 60 \mathrm{yr}$ ), gender (male vs. female), $J A K 2$-positive status (no vs. yes) and TE prior to diagnosis (no vs. yes). Type I error was not adjusted for multiple testing, and therefore, the results of inferential statistics are descriptive only. Statistical analysis was performed using the open-source R statistical software package, version 3.1.2 (The R Foundation for Statistical Computing, Vienna, Austria), and statistical tests were interpreted at a $5 \%$ significance level.

\section{Study approval}

The study was approved by the ETT-TUKEB and was performed in compliance with the Declaration of Helsinki. Patient consent was not obtained, but the data are presented on a group basis and there is no risk of patient identification.

\section{Results}

\section{Database and extraction}


During the first year of Registry data collection, 15 major or smaller haematological centres provided patient data, yielding 350 evaluable patients with ET. Of these, 139 patients with ET were treated with anagrelide and 141 were treated with hydroxyurea + aspirin. Patients were followed up for a median of $6 \mathrm{yr}$ (Table 1 ).

Table 1. Characteristics of patients with ET treated with anagrelide vs. hydroxyurea + aspirin

$\begin{array}{cccc}\text { Anagrelide } & \begin{array}{c}\text { Hydroxyurea }+ \\ \text { aspirin }\end{array} & \text { Total } & P \text { value } \\ N=139 & N=141 & N=280\end{array}$

Gender

Male, $n(\%)$

Female, $n(\%)$

Age at diagnosis, yr, median

(minimum-maximum)

Mean \pm standard deviation

Age at diagnosis categorised, $\mathrm{yr}$

$$
\begin{aligned}
& <60 \mathrm{yr}, n(\%) \\
& \geq 60 \mathrm{yr}, n(\%)
\end{aligned}
$$

$J A K 2$ positive, yes, $n(\%)$

Length of follow-up, yr, median

(minimum-maximum)

Mean \pm standard deviation

Landolfi risk summary score, median

$$
\begin{aligned}
& \text { (minimum-maximum) } \\
& \text { Mean } \pm \text { standard deviation }
\end{aligned}
$$

TE prior to diagnosis, yes, $n(\%)$

TE after diagnosis, yes, $n(\%)$

Total

$$
\begin{aligned}
& \text { Arterial minor } \\
& \text { Arterial major } \\
& \text { Venous minor } \\
& \text { Venous major }
\end{aligned}
$$

Bleeding event, yes, $n(\%)$
$41(29.5) \quad 48(34.0)$

$98(70.5) \quad 93(66.0)$

59.8

64.3

(25.1-91.1) (28.9-89.3)

$58.1 \pm 14.462 .6 \pm 11.1$

$71(51.1) \quad 57(40.4)$

68 (48.9) 84 (59.6)

79 (57.2)ㅁ $94(66.7)$

7

$(0-25)$

$8.0 \pm 5.5 \quad 6.6 \pm 5.3$

4.5

4.5

$(2.0-10.5) \quad(1.5-10.0)$

$5.1(1.7)$

$5.1(1.8)$

$24(17.3) \quad 31(22.0)$

$21(15.1) \quad 70(49.6)$

$6(4.3)$

$31(22.1) \underline{b}$

$2(1.4)$

$3(2.1)$

5 (3.6)

$30(21.3)$

12 (8.6)

$8(5.7)$

4 (2.9)

$2(1.4)$
89 (31.8)

$191(68.2) \quad 0.443$

61.9

(25.1-

91.1)

0.004

$60.4 \pm 13.0$

$128(45.7)$

$152(54.3)$

0.093

173 (62.0) 0.111

6

$(0-25) \quad 0.035$

$7.3 \pm 5.5$

4.5

$(1.5-10.5) \quad 0.790$

$5.1(1.7)$

55 (19.6) $\quad 0.368$

$91(32.5)<0.001 \underline{\mathrm{a}}$

$37(13.3)<0.001 \underline{\mathrm{a}}$

$5(1.8) \quad 0.999 \underline{a}$

35 (12.5) <0.001

$20(7.1) \quad 0.363 \underline{a}$

$6(2.1) \quad 0.446 \underline{b}$

- ET, essential thrombocythaemia; TE, thromboembolic event.

- a Compared with patients categorised as 'no, $n(\%)$ '.

- b Missing data for one patient.

\section{Patient characteristics and thrombotic risk}

In both groups, the male-to-female ratio was approximately $1: 2$, and most patients were JAK2 V617F-positive (Table 1). The Landolfi risk summary score was median 4.5 (total 
range 1.5-10.5) for both the anagrelide and hydroxyurea + aspirin groups. There was no significant between-group difference in gender, age at diagnosis categorised ( $<60$ and $\geq 60 \mathrm{yr}$ ), $J A K 2 \mathrm{~V} 617 \mathrm{~F}$ positivity (yes vs. no) or Landolfi risk summary score.

Prior to diagnosis, TEs were reported in similar numbers of patients in each group (Table 1 ). After diagnosis, TEs were reported in $15.1 \%$ of patients in the anagrelide group and $49.6 \%$ of patients in the hydroxyurea + aspirin group $(P<0.001$; Table 1$)$. The numbers of major arterial and major venous events were similar between the groups. However, there were more than fivefold between-group differences in both minor arterial and minor venous events (both $P<0.001$ ), which were more frequently reported in the hydroxyurea + aspirin group (Table 1). There were four haemorrhagic complications in the anagrelide group and two in the hydroxyurea + aspirin group, although the difference was not significant. Arterial and venous TEs according to treatment group and gender, and treatment group and $<60 \mathrm{yr} / \geq 60 \mathrm{yr}$ are shown in Table $\underline{2}$.

Table 2. TEs occurring after diagnosis according to gender and age group of patients with ET

$$
\begin{array}{cccc}
\multicolumn{2}{c}{\text { Anagrelide }} & \multicolumn{2}{c}{\text { Hydroxyurea + aspirin }} \\
\multicolumn{2}{c}{\boldsymbol{N = \mathbf { 1 3 9 }}} & \multicolumn{2}{c}{\boldsymbol{N}=\mathbf{1 4 1}} \\
\text { Male } & \text { Female } & \text { Male } & \text { Female } \\
n=41 & n=98 & n=48 & n=93
\end{array}
$$

Gender Male Female Male Female

TE after diagnosis, yes, $n(\%)$

$$
\begin{array}{rlllll}
\multicolumn{1}{r}{\text { Total }} & 5(12.2) \underline{\mathrm{b}} & 16(16.3) \underline{\mathrm{b}} & 24(50.0) \underline{\mathrm{c}} & 46(49.5) \underline{\mathrm{c}} & <0.001 \\
\text { Arterial minor } & 2(4.9) & 4(4.1) \underline{\mathrm{b}} & 13(27.1) \underline{\mathrm{c}} & 18(19.6) \underline{\mathrm{d}} & <0.001 \\
\text { Arterial major } & 1(2.4) & 1(1.0) & 1(2.1) & 2(2.2) & 0.94 \\
\text { Venous minor } & 1(2.4) & 4(4.1) \underline{\mathrm{b}} & 7(14.6) & 23(24.7) \underline{\mathrm{c}} & <0.001 \\
\text { Venous major } & 1(2.4) & 11(11.2) & 5(10.4) & 3(3.2) & 0.075 \\
\text { Bleeding event } & 1(2.4) & 3(3.1) & 1(2.1) & 1(1.1) & 0.94 \\
\text { Age group } & <60 \mathrm{yr} & \geq 60 \mathrm{yr} & <60 \mathrm{yr} & \geq 60 \mathrm{yr} & \\
& n=71 & n=68 & n=57 & n=84 &
\end{array}
$$

TE after diagnosis, yes, $n(\%)$

$\begin{array}{rlllll}\text { Total } & 10(14.1) & 11(16.2) \underline{\mathrm{b}} 28(49.1) \underline{\mathrm{c}} & 42(50.0) \underline{\mathrm{c}} & <0.001 \\ \text { Arterial minor 5 (7.0) } \underline{\mathrm{b}} & 1(1.5) \underline{\mathrm{b}} & 11(19.6) \underline{\mathrm{d}} & 20(23.8) \underline{\mathrm{c}} & <0.001 \\ \text { Arterial major 0 (0) } & 2(2.9) & 2(3.5) & 1(1.2) & 0.40 \\ \text { Venous minor 2(2.8) } & 3(4.4) & 11(19.3) & 19(22.6) \underline{\mathrm{c}} & <0.001 \\ \text { Venous major } & 5(7.0) & 7(10.3) & 5(8.8) & 3(3.6) & 0.42 \\ \text { Bleeding event } & 2(2.8) & 2(2.9) & 1(1.8) & 1(1.2) & 0.90\end{array}$

- ET, essential thrombocythaemia; TE, thromboembolic event.

- a Chi-square comparison of categorical variables between anagrelide/male vs. anagrelide/female vs. hydroxyurea + aspirin/male vs. hydroxyurea + aspirin/female; and between anagrelide/ $<60$ vs. anagrelide $/ \geq 60$ vs. hydroxyurea + aspirin $/<60$ vs. hydroxyurea + aspirin $/ \geq 60$.

- b Lower than expected $(P<0.05)$.

- c Higher than expected $(P<0.05)$.

- d Missing data for one patient. 
There was a significant between-group difference in the continuous variables, median age at diagnosis (older in the hydroxyurea + aspirin group) and length of follow-up (shorter in the hydroxyurea + aspirin group) (Table 1 ). Regression analysis indicated that these findings did not influence the incidence of TE; medication, Landolfi risk summary score and TE prior to diagnosis only were found to influence the incidence of TE (Table $\underline{3}$ ).

Table 3. Influence of ET cohort characteristics on the occurrence of TE

\section{Variables}

Medication (anagrelide vs. hydroxyurea + aspirin)

Gender (male vs. female)

Age at diagnosis categorised ( $<60$ yr vs. $\geq 60$

yr)

$J A K 2$ positive (no vs. yes)

Length of follow-up (yr)

Landolfi risk summary score

TE prior to diagnosis (no vs. yes)

$\begin{array}{ccc}P & \operatorname{Exp}(B): \text { odds } & \operatorname{EXP}(B): 95 \% \\ \text { value } & \text { ratio } & \text { CI }\end{array}$

$<0.0018 .551$

$4.250,17.207$

$0.447 \quad 1.297$

$0.663,2.537$

$0.218 \quad 0.638$

$0.311,1.305$

$0.538 \quad 1.227$

$0.640,2.353$

$0.750 \quad 1.010$

$0.951,1.072$

$<0.001 \quad 1.582$

$1.235,2.027$

$0.016 \quad 3.195$

- ET, essential thrombocythaemia; TE, thromboembolic event.

- Logistic regression with categorical age (included cases, $n=279$ ); the dependent variable is the number of patients with a TE after diagnosis ('yes').

\section{Discussion}

In this evaluation of data on ET patients in the Hungarian MPN Registry, treatment with anagrelide significantly decreased the number of patients experiencing minor arterial and minor venous TEs compared with hydroxyurea + aspirin over a median of $6 \mathrm{yr}$. In this ET patient cohort, risk of TE after diagnosis was significantly increased by Landolfi risk summary score and if the patient had experienced a TE prior to diagnosis. No other risk factor for TE was identified. Anagrelide has demonstrated efficacy in reducing platelet counts in patients with ET and thrombocytosis due to myeloproliferative disorders, and control of platelet counts is reported to reduce the incidence of TEs in ET 17.

Our findings are contradictory to previous studies comparing hydroxyurea with anagrelide, which have also demonstrated conflicting results $\underline{15}, \underline{16}$. A randomised trial of 809 with ET (Polycythemia Vera Study Group diagnostic criteria) who were at high risk for vascular events showed hydroxyurea + low-dose aspirin was superior to anagrelide + low-dose aspirin in reducing the risk of arterial thrombosis and serious haemorrhage, after a median follow-up of 39 months 15 . A decreased rate of venous thromboembolism was observed in the anagrelide group, although patients were more likely to discontinue treatment due to adverse events. Another comparative study in 259 previously untreated, high-risk patients with ET (WHO diagnostic criteria) found that there was no significant difference between the hydroxyurea and anagrelide groups at 6,12 and 36 months regarding the frequency of ET-related major and minor thrombo-haemorrhagic events $\underline{16}$. A meta-analysis of these trials reported that hydroxyurea and anagrelide were equally effective for protection against TEs but that there were fewer major bleeding events with hydroxyurea $\underline{18}$. Notably, our study had 
a longer follow-up period (median of 72 months) than either of these studies, suggesting that there may be an increase in TEs in ET patients treated with hydroxyurea over time.

While the reduction in venous thromboembolism by anagrelide compared to hydroxyurea appears to be consistent between previous studies $\underline{15}, \underline{16}$ and in this study, there is a discrepancy between our findings and those reported by Harrison et al. 15 regarding arterial events. Harrison et al. 15 observed arterial complications in $9.1 \%$ of patients in the anagrelide + aspirin group versus $4.2 \%$ in the hydroxyurea + aspirin group, whereas this study there were $5.7 \%$ versus $24.1 \%$ in the anagrelide and the hydroxyurea + aspirin groups, respectively. Notably, the majority of arterial thromboses prevented by hydroxyurea + aspirin were TIAs the former study. In contrast, we found a pronounced reduction in minor arterial complications (including TIAs) by anagrelide. We cannot specifically address the reason behind this reduction as the questionnaire used to compile Registry data grouped all minor events rather than detailing each event individually. However, because minor complications were perhaps less remarkable than major events, doctors and patients may have been less inclined to register them. These findings suggest a need to update this Registry questionnaire, to document the specific arterial and venous events experienced by patients on these treatments.

Consistent with our findings, it is well established that the strongest risk factor for arterial and venous thrombosis is a history of these events $\underline{19}$. Additional risk factors for arterial thrombosis in ET include age $>60 \mathrm{yr}$ and the presence of JAK2V617F and for venous thrombosis is male gender $\underline{8}$. It is interesting to note that despite a greater number of TEs in patients treated with hydroxyurea + aspirin, there was no between-group difference in the proportions of older patients at diagnosis or JAK2V617F-positive patients. Notably, identification of JAK2V617F does not necessarily change risk stratification of patients with ET, but age of $\geq 60 \mathrm{yr}$ and history of thrombosis are used to classify patients as low-, intermediate- and high-risk categories $\underline{9}$.

To identify more clearly a patient's risk of vascular events, the Landolfi criteria can be used to assign a patient to a certain risk level based on a scoring system 13. Age is considered progressively rather than on a single threshold level, and other possible risk factors such as a past history of thrombosis, smoking, and high leucocyte and platelet counts are included. Our study showed that the Landolfi risk summary score is a significant risk factor for TE after diagnosis. Healthcare professionals in haematological centres in Hungary can access these data in $<10$ min giving the consulting physician rapid assessment of patient TE risk. Landolfi criteria have not previously been used in clinical studies and, recognising the association between the Landolfi summary score with TE risk after diagnosis, should be considered in clinical practice and in the design of future studies. Furthermore, our study highlights the importance of controlling those Landolfi risk factors that can be modified.

In the present study, data on patients with ET were collected in line with WHO diagnostic criteria $\underline{1}$, and thrombotic risk and risk-adapted treatment characteristics were stratified according to Landolfi criteria $\underline{13}$. However, as these patients were treated according to individual clinical practice and not in a randomised controlled trial, the influence of previous treatments on the risk of thrombosis cannot be ruled out. Additionally, unlike patients in the anagrelide group, patients receiving hydroxyurea also received aspirin. Aspirin has been associated with a reduction in the incidence of venous thrombosis in JAK2V617F-positive low-risk patients with ET and, in those patients with cardiovascular risk factors, the rate of arterial thrombosis 20 . This protective effect is recognised in treatment guidelines for patients 
with ET both with and without a previous history of thrombosis 9 . The contribution of aspirin in TE prevention could not be determined in this study in which it was used in combination with hydroxyurea. On the other hand, bleeding associated with aspirin may be promoted in ET 21, although there was no significant difference in the small numbers of bleeding complications in our study.

Compared to major complications, minor arterial complications are more difficult to define, and their diagnosis may be more subjective. This may have led to a bias in this study because doctors providing the registry data were aware of the patients' treatment. This potential limitation of the study presents difficulties to drawing definitive conclusions that support treatment recommendations.

Our finding that hydroxyurea + aspirin treatment of patients with ET significantly increased the risk of minor arterial and venous TEs compared with anagrelide should be considered in the light of current recommendations. These consider that patients with ET aged $\geq 60 \mathrm{yr}$ with no thrombotic event history, and patients of any age with a history of arterial and/or venous TE receive hydroxyurea + aspirin $\underline{9}$. However, guidelines $\underline{9}$ advise against the use of anagrelide for the treatment of ET because of its previously reported association with increased risk of arterial thrombosis and major bleeding $\underline{9}$. Comparison of these two treatment regimens regarding the likelihood of TEs warrants further investigation among larger ET cohorts from real-life clinical practice.

\section{Acknowledgements}

The authors would like to thank Mónika Horváth, Judit Halász, Dr Jakucs János, Dr Szerafin László, Dr Kiss Miklós, Dr Raposa Tibor, Dr Hamvas József, Dr Gasztonyi Zoltán, Dr Bodnár Mária, Dr Dömötör Mária, Dr Altay Elvira and Dr Palaczki Aranka for data entry; Dr Wolfgang Schimetta for statistical analyses; and Dr Susan Libretto for preparation of the manuscript and for editorial assistance. This work was supported by the participating hospitals. The preparation of this manuscript and statistical analyses were supported by AOP Orphan Pharmaceuticals AG. The authors do not have financial and/or personal relationships with other people or organisations that could inappropriately influence this work. 
- 1Vardiman JW, Thiele J, Arber DA, et al. The 2008 revision of the World Health Organization (WHO) classification of myeloid neoplasms and acute leukemia: rationale and important changes. Blood 2009;114:937-51.

$\underline{\text { Crossref }} \underline{\text { CAS PubMed }} \underline{\text { Web of Science }} \underline{R \text { Google ScholarUniversity of Debrecen }}$

- 2Tefferi A, Vardiman JW. Classification and diagnosis of myeloproliferative neoplasms: the 2008 World Health Organization criteria and point-of-care diagnostic algorithms. Leukemia 2008;22:14-22.

$\underline{\text { Crossref }} \underline{\text { CAS }} \underline{\text { PubMed }} \underline{\text { Web of Science }{ }^{\circledR} \text { Google ScholarUniversity of Debrecen }}$

- 3Tefferi A. Novel mutations and their functional and clinical relevance in myeloproliferative neoplasms: JAK2, MPL, TET2, ASXL1, CBL, IDH and IKZF1. Leukemia 2010;24:1128-38.

\section{$\underline{\text { Crossref }} \underline{\text { CAS PubMed Web of Science }{ }^{\circledR} \text { Google ScholarUniversity of Debrecen }}$}

- 4Pardanani A, Lasho TL, Finke C, Hanson CA, Tefferi A. Prevalence and clinicopathologic correlates of JAK2 exon 12 mutations in JAK2V617F-negative polycythemia vera. Leukemia 2007;21:1960-3.

\section{$\underline{\text { Crossref }} \underline{\text { CAS PubMed Web of Science }} \underline{\circledR}$ Google ScholarUniversity of Debrecen}

- 5Vannucchi AM, Antonioli E, Guglielmelli P, Pardanani A, Tefferi A. Clinical correlates of JAK2 $2617 \mathrm{~F}$ presence or allele burden in myeloproliferative neoplasms: a critical reappraisal. Leukemia 2008;22:1299-307.

\section{$\underline{\text { Crossref }} \underline{\text { CAS }} \underline{\text { PubMed Web of Science }{ }^{\circledR} \text { Google ScholarUniversity of Debrecen }}$}

- 6Passamonti F, Rumi E, Pietra D, et al. A prospective study of 338 patients with polycythemia vera: the impact of JAK2 (V617F) allele burden and leucocytosis on fibrotic or leukemic disease transformation and vascular complications. Leukemia 2010;24:1574-9.

\section{$\underline{\text { Crossref }} \underline{\text { CAS PubMed Web of Science }{ }^{\circledR} \text { Google ScholarUniversity of Debrecen }}$}

- 7Barbui T, Thiele J, Passamonti F, et al. Survival and disease progression in essential thrombocythemia are significantly influenced by accurate morphologic diagnosis: an international study. J Clin Oncol 2011;29:3179-84.

\section{Crossref PubMed Web of Science $\underline{\circledR}$ Google ScholarUniversity of Debrecen}

- 8Carobbio A, Thiele J, Passamonti F, et al. Risk factors for arterial and venous thrombosis in WHO-defined essential thrombocythemia: an international study of 891 patients. Blood 2011;117:5857-9. 
- 9Tefferi A, Barbui T. Polycythemia vera and essential thrombocythemia: 2015 update on diagnosis, risk-stratification and management. Am J Hematol 2015;90:62-73.

Wiley Online Library CAS PubMed Web of Science ${ }^{\circledR}$ Google ScholarUniversity of $\underline{\text { Debrecen }}$

- 10 Crisa E, Venturino E, Passera R, et al. A retrospective study on 226 polycythemia vera patients: impact of median hematocrit value on clinical outcomes and survival improvement with anti-thrombotic prophylaxis and non-alkylating drugs. Ann Hematol 2010;89:691-9.

Crossref PubMed Web of Science ${ }^{\circledR}$ Google ScholarUniversity of Debrecen

- 11Tefferi A, Elliott M. Thrombosis in myeloproliferative disorders: prevalence, prognostic factors, and the role of leukocytes and JAK2V617F. Semin Thromb Hemost 2007;33:313-20.

\section{$\underline{\text { Crossref }} \underline{\text { CAS PubMed Web of Science }{ }^{\circledR} \text { Google ScholarUniversity of Debrecen }}$}

- 12Dombi P, Illés Á, Demeter J, Homor L, Simon Z, Udvardy M, Egyed M. Development of the Philadelphia negative chronic myeloproliferative neoplasia registry in Hungary. Orv Hetil 2016;157:98-103.

\section{Crossref PubMed Web of Science ${ }^{\circledR}$ Google ScholarUniversity of Debrecen}

- 13Landolfi R, Gennaro L. Prevention of thrombosis in polycythemia vera and essential thrombocythemia. Haematologica 2008;93:331-5.

$\underline{\text { Crossref }} \underline{\text { CAS }} \underline{\text { PubMed Web of Science }{ }^{\circledR G} \text { Google ScholarUniversity of Debrecen }}$

- 14Masszi T. Novel approaches in the diagnosis and treatment of chronic myeloproliferative illnesses. Magy Belorv Arch 2014;67:354-7.

\section{Google ScholarUniversity of Debrecen}

- 15Harrison CN, Campbell PJ, Buck G, et al. Hydroxyurea compared with anagrelide in high-risk essential thrombocythemia. N Engl J Med 2005;353:33-45.

\section{Crossref CAS PubMed Web of Science ${ }^{\circledR}$ Google ScholarUniversity of Debrecen}

- 16Gisslinger H, Gotic M, Holowiecki J, Penka M, Thiele J, Kvasnicka HM, Kralovics R, Petrides PE; ANAHYDRET Study Group. Anagrelide compared to hydroxyurea in WHO-classified essential thrombocythemia: the ANAHYDRET Study, a randomized controlled trial. Blood 2013;121:1720-8.

\section{$\underline{\text { Crossref }} \underline{\text { CAS }} \underline{\text { PubMed Web of Science }{ }^{\circledR} \text { Google ScholarUniversity of Debrecen }}$}

- $\quad$ 17Steurer M, Gastl G, Jedrzejczak WW, Pytlik R, Lin W, Schlögl E, Gisslinger H. Anagrelide for thrombocytosis in myeloproliferative disorders: a prospective study to assess efficacy and adverse event profile. Cancer 2004;101:2239-46. 


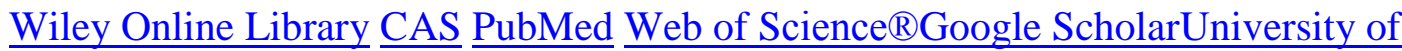
Debrecen

- 18Samuelson B, Chai-Adisaksopha C, Garcia D. Anagrelide compared with hydroxyurea in essential thrombocythemia: a meta-analysis. J Thromb Thrombolysis 2015;40:474-9.

$\underline{\text { Crossref }} \underline{\text { CAS PubMed Web of Science }{ }^{\circledR} \text { Google ScholarUniversity of Debrecen }}$

- 19Tefferi A, Barbui T. Essential thrombocythemia and polycythemia vera: focus on clinical practice. Mayo Clin Proc 2015;90:1283-93.

$\underline{\text { Crossref PubMed Web of Science }{ }^{\circledR} \text { Google ScholarUniversity of Debrecen }}$

- 20Alvarez-Larrán A, Cervantes F, Pereira A, et al. Observation versus antiplatelet therapy as primary prophylaxis for thrombosis in low-risk essential thrombocythemia. Blood 2010;116:1205-10.

Crossref $\underline{\text { CAS }} \underline{\text { PubMed Web of Science }{ }^{\circledR} \text { Google ScholarUniversity of Debrecen }}$

- 21Cortelazzo S, Marchetti M, Orlando E, Falanga A, Barbui T, Buchanan MR. Aspirin increases the bleeding side effects in essential thrombocythemia independent of the cyclooxygenase pathway: role of the lipoxygenase pathway. Am J Hematol 1998;57:277-82.

Wiley Online Library CAS PubMed Web of Science ${ }^{\circledR}$ Google ScholarUniversity of Debrecen 